\title{
PSICOLOGIA E SURDEZ: GOVERNAMENTO DA DIFERENÇA E OUTRAS MAR- GENS POSSÍVEIS
}

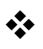

Liliane Moreira de Oliveira

Centro Universitário Metodista do Sul - IPA - Brasil

Oriana Holsbach Hadler

Centro Universitário Metodista do Sul - IPA - Brasil

\section{Resumo}

Em uma época em que muito se fala sobre inclusão de pessoas com deficiência e sobre a necessidade de preparação para o exercício desta inclusão, o presente artigo se propõe questionar em que momento a surdez passa a ser compreendida como deficiência, sendo incorporada às Políticas Públicas de Inclusão a partir de uma produção acerca de suas especificidades e saberes científicos. Nesse sentido, o presente artigo visa a problematizar o momento e a maneira como as pessoas surdas passam a ser público-alvo da Psicologia. Propõe-se, ao longo da discussão, a compreensão dos movimentos de normatização, normalização e governamento da diferença, visando apresentar a possibilidade e/ou necessidade de lançar um novo olhar sobre a surdez com o intuito de modificar a relação entre Psicologia e Surdez, distanciando-se da relação saber-objeto em que tal encontro está instituído. Para tal serão tensionados alguns depoimentos e discursos presentes na fala de profissionais da área, identificando de que lugar a Psicologia fala atualmente e como tais narrativas dão visibilidade a processos de subjetivação da população surda.

Palavras-chave: Surdez. Psicologia. Políticas de Inclusão. Governamento.

\section{Introdução}

"A gaivota cresceu e voa com suas próprias asas. Olho do mesmo modo como que poderia escutar. Meus olhos são meus ouvidos. Escrevo do mesmo modo que me exprimo por sinais. Minhas mãos são bilíngues. Ofereço-lhes minha diferença. Meu coração não é surdo a nada neste duplo mundo...". 
Quando a surdez e a questão das políticas de inclusão voltadas a este público passam a ser tomadas enquanto demanda para a Psicologia? O período de graduação em Psicologia foi acompanhado por uma grande inquietação da primeira autora quanto a surdez e a questão de políticas de inclusão voltadas a este público na sociedade. Tal processo de desassossego devese, em parte, a movimentos recentes que envolvem grandes esforços com relação ao tema da inclusão social das pessoas com deficiência no cenário brasileiro contemporâneo. Sendo assim, são lançadas as questões: o que é entendido como deficiência? Como se classificam e equacionam a categoria "pessoas com deficiência" no país? Quem faz esta classificação, os ditos "deficientes" ou os "normais" a partir de seu discurso de verdade sobre o outro? O que atravessa e produz o discurso de inclusão social e como esta noção passa a atravessar e constituir uma preocupação na formação em Psicologia? Tais questionamentos culminaram em certos tensionamentos sobre este processo denominado inclusão social, especificamente voltado a pessoas com surdez, frequentemente denominadas com "dificuldades de comunicação", ou "deficientes da linguagem" (AMARAL e PARAÍSO, s/d), uma vez que possuem uma forma distinta de comunicação gestual.

$\mathrm{Na}$ busca por respostas, ou maiores incitações, foram encontrados dados levantados pela Organização Mundial de Saúde (OMS) em 1993 (BRASIL, 2010b), que estima a porcentagem de pessoas com deficiência no mundo, e pelo Censo do Instituto Brasileiro de Geografia e Estatística - IBGE (BRASIL, 2010a) que traz dados percentuais sobre a população surda do Brasil. Segundo a OMS, cerca de $10 \%$ da população de qualquer país em tempos de paz possui algum tipo de deficiência. Considerando apenas a população brasileira e a parcela de deficientes auditivos, foco deste trabalho, esta população somava, no início dos anos 1990, aproximadamente 2.250 .000 pessoas, cerca de $1,5 \%$ do total de habitantes do país. Já em 2010 o levantamento realizado pelo Censo indicava que cerca de $23,92 \%$ da população brasileira possuía deficiência auditiva. Contudo, o número atual de surdos no país é indefinido, pois ainda não se encontrou uma maneira efetiva e funcional de realizar tal medição. Pois, tanto o Censo como a Pesquisa Nacional por Amostragem Domiciliar (Pnad), responsáveis pelas medições estatísticas populacionais no Brasil, baseiam-se na resposta positiva da população para os quesitos de maior grau de deficiência, o que leva à inexistência de dados e informações precisos de abrangência nacional.

Porém, mesmo considerando apenas os levantamentos realizados em 1993 e 2010, o número de pessoas com deficiência auditiva é consideravelmente alto e paradoxalmente, conforme observado a partir de experiências de pesquisa, tendo pouca visibilidade, principalmen- 
te na área da saúde, onde, segundo levantamento realizado junto aos órgãos de representação dos profissionais da Psicologia - Conselho Regional de Psicologia e Conselho Federal de Psicologia - não há registro de profissionais habilitados para realizar atendimento na língua própria dos surdos, a Língua Brasileira de Sinais. Ao que tudo indica, como nos mostram os dados anteriormente referenciados, vive-se em um duplo mundo, como coloca Laborit na epígrafe que abre este trabalho; um mundo binário onde se separam subjetividades entre normais e anormais, saudáveis e deficientes. Tendo em vista tais apontamentos, questiona-se: como a Psicologia vem tomando a surdez e que práticas vêm sendo desenvolvidas nesse âmbito? Da mesma forma, interessa saber: como essa ciência vem pensando a inclusão social e como o público surdo é "escutado" pelos profissionais da área?

Compreendendo que atualmente dispõe-se de diferentes entendimentos de inclusão social, bem como de entendimentos cientificistas de deficiência e surdez, apresenta-se a definição presente nas páginas da Política Nacional de Saúde da Pessoa Portadora de Deficiência - PNSPPD (BRASIL, 2010b), que toma inclusão social como:

\footnotetext{
"o processo pelo qual a sociedade se adapta para incluir, em seus sistemas sociais gerais, pessoas com necessidades especiais e, simultaneamente, estas se preparam para assumir seus papéis na sociedade. A inclusão social constitui, então, um processo bilateral no qual as pessoas, ainda excluídas, e a sociedade buscam, em parceria, equacionar problemas, decidir sobre soluções e efetivar a equiparação de oportunidades para todos" (SASSAKI, 1997 apud BRASIL, 2010b).
}

Em contrapartida, Lopes (2011, p.7), tensiona este conceito criticando seu binarismo, colocando-o como o "conjunto de práticas sociais, culturais, educacionais, de saúde, entre outras, voltadas para a população que se quer disciplinar, acompanhar e regulamentar". Assim, ao tomar o conceito de inclusão social, é importante desnaturalizá-lo, tomando-o como espaço que se transforma conforme condições sócio-históricas, esquemas culturais e práticas discursivas que passam a compô-lo conforme a emergência de necessidades sociais.

Nesse âmbito, as discussões sobre inclusão social hoje, pelo menos no cenário brasileiro, passam a refletir toda uma discussão voltada a categorias tidas como "deficientes" e/ou em "situação de vulnerabilidade social". Dito de outra forma, na história da inclusão perpassa a constituição de um olhar dicotômico que envolve aqueles tomados como "os excluídos". Inclusive, no palco das legislações brasileiras, o conceito de deficiência aparece em 1999, correspondendo a "toda perda ou anormalidade de uma estrutura ou função psicológica, fisiológica ou anatômica que gere incapacidade para o desempenho de atividade, dentro do padrão considerado normal para o ser humano" (BRASIL, 1999, s/p, grifos das autoras). Sob tal ponto de vista, a deficiência passa a ser marcada por um sentido de falta, de inferiori- 
dade ao marcar sujeitos incapazes e, além disso, um sentido de homogeneização de determinados padrões humanos generalizados, sem considerar aspectos singulares e experiências sociais das culturas. Assim também a surdez passa a ser caracterizada, "pela perda total ou parcial da capacidade de ouvir, manifesta-se como surdez leve e moderada e surdez severa ou profunda" (BRASIL, 2010b, p.6, grifos das autoras). Marcada pela perda, e não pela diferença. Parece, desta forma, que a produção de marcas identitárias vêm convocar a população surda já a priori como aqueles a quem lhes falta algo, aqueles que têm incapacidades para atividades, em vez de visibilizar suas potencialidades.

A partir do desconforto com essa situação, o objetivo deste artigo será problematizar como a Psicologia vem tomando a surdez e que práticas emergem para o atendimento a este público, ou seja, a ideia é desnaturalizar o que está sendo feito especificamente para esta população historicamente excluída (PERLIN, 2002) de seu direito ao cuidado e ao acesso integral à saúde. Para tal, o presente artigo buscará tensionar as Políticas Públicas pensadas para Pessoas com Deficiência, tendo como material referência a Política Nacional de Saúde da Pessoa com Deficiência - PNSPPD (BRASIL, 2010b) a fim de nortear a discussão, visto que ela pensa o indivíduo em todas as áreas de suas vidas, incluindo a saúde. Entretanto, considerando que não se pode falar de acesso sem relacionar com os direitos humanos, tomar-se-á, também, o documento “Avanços das Políticas Públicas para as Pessoas com Deficiência: Uma análise a partir das Conferências Nacionais" (BRASIL, 2012) - pensado e elaborado para determinados grupos da população - uma vez que eles interferem diretamente no acesso buscado e na preparação dos trabalhadores da área, que terão de se adequar à demanda para possibilitar uma efetiva inclusão.

Neste sentido, o artigo inicialmente explanará sobre o entendimento histórico de surdez e deficiência, bem como de Estado e deficiência, para compreender o movimento governamental que passa a possibilitar a criação e o mantimento de práticas de inclusão. A seguir, discutir-se-á sobre a relação entre Psicologia e deficiência, utilizando-se alguns autores que se dedicam, também, a pensar como se dá e se deu tal relacionamento. Finalizando, serão mapeados alguns discursos presentes no campo das práticas psicológicas a fim de tensioná-los quanto ao olhar, escuta e visibilidade que a surdez passa a ter para esta ciência.

\section{Governamento da diferença surda}

Antes de contextualizar diretamente a construção histórica das práticas de atenção voltadas para a surdez, cabe ressaltar que, para a discussão sobre o processo histórico vivenciado 
entre surdez, deficiência, Estado e Psicologia tomar-se-ão emprestados alguns operadores foucaultianos, tais como os conceitos de governamentalidade, normalização e normatização, pois auxiliarão na compreensão de condições de possibilidade para as atuais Políticas de Inclusão. Assim, normatização refere-se à criação e ao estabelecimento de regras e modelos sociais de normalidade, enquanto a normalização tem a função de fazer com que todos caibam, ou se aproximem ao máximo das normas e dos modelos preestabelecidos, a governamentalidade, por sua vez, compreende ambas as anteriores, pois se refere a "todo o conjunto de ações de poder que objetivam conduzir ou estruturar ações próprias ou de outrem" (VEIGA-NETO e LOPES, 2007). Dito de outra forma, a governamentalidade é responsável por todas as ações de controle próprio e dos outros que, desde pequenos, passam a conduzir sutilmente a conduta de si e de outrem; ou seja, o aprendizado com maestria, de determinado modo de ser, pensar e agir.

Vale ressaltar que a governamentalidade está intrinsecamente ligada a um conjunto de práticas que foram surgindo a partir de modificações originadas no século XVI. Essas remetem ao governo da pastoral cristã, em que os súditos, para que suas almas fossem salvas, tinham suas condutas veladas não somente pelos clérigos, mas também por si mesmos. Tratava-se de mudanças nos modos de governo: ocorre a transição de uma sociedade feudal, cujo governo centrava-se no território, para uma sociedade disciplinar, de controle e regulamentação que ultrapassava questões de espaço físico. Compreender essa passagem é essencial, pois conforme Foucault (2007, p. 292) revela, "desde o século XVIII, vivemos na era da governamentalidade".

Sendo assim, ao olhar para a história da surdez, se buscará atentar como certos modos de ser passam a conduzir a população surda e, principalmente, como foram sendo produzidas transformações discursivas e não discursivas voltadas a este grupo populacional; mudanças estas que são herdadas na forma como a Psicologia passa a olhar (e intervir) sobre a surdez. A isso nos filiamos à Thoma e Hillesheim (2011), uma vez que estas autoras problematizam o campo das políticas de inclusão a partir do viés do governamento das diferenças, visando explicitar as condições que determinam certas formas de agir, pensar, olhar para o que é tomado como "diferente". Dito de outra forma, a seguir serão contados como determinados olhares, práticas estigmatizadas e políticas de cuidado para a população surda apresentam formas de objetivar e normatizar a surdez: muitas vezes enquanto deficiência, outras como diferença “especial”. Nesse sentido, tomar-se-á o operador governamentalidade para pensar como a população surda vem sendo regida na sociedade contemporânea, principalmente no que tange 
o campo das práticas psicológicas voltadas para esse público. Para tal, este artigo iniciará trilhando um breve histórico de sua constituição.

\section{Visão histórica da surdez}

O povo surdo, como eles próprios se denominam e conforme Ströbel (2007) convoca enquanto conjunto de sujeitos surdos que não habitam o mesmo local, mas que estão ligados por sua origem, compartilhando movimentos sócio-históricos, sempre foi alvo de discriminação e isolamento, sendo essa uma das explicações para a não existência de sua história fielmente documentada. Como toda população tomada como "inferior" ou "deficiente", também os surdos tiveram sua história escrita a partir das interpretações feitas por grupos hegemônicos ou ditos "normais", neste caso os ouvintes, que naturalmente os descrevem como pessoas inadequadas, não quistas e inábeis. Tais pronomes são explicados pelo fato de a história da surdez estar intimamente relacionada com a história da educação geral, uma vez que tal singularidade (vista no decorrer da história como deficiência) torna-se mais perturbadora e problemática quando há o surgimento da escola e a população surda começa a conviver em um espaço comum que passa a exigir uma padronização referente às condições de aprendizagem e comunicação.

Anteriormente ao surgimento da escola, encontram-se registros da existência de surdos desde 1660 a.C., marcados sempre pelo signo da diferença e o direito da sua existência construído sob o enfoque da filantropia, enquanto uma população que não deveria ser protegida necessariamente, porém, tampouco referenciada como maldita: a surdez apenas fazia parte de um conjunto de agrupamentos humanos acometidos de sofrimento, os quais conseguiriam viver protegidos somente por leis cunhadas em aspectos religiosos (PERLIN, 2002). Tal configuração muda na Grécia Antiga, quando o direito à vida passa a ser apenas daqueles considerados laboralmente úteis, portanto, o sujeito surdo não correspondia a estas expectativas. Há registros de que o fundador de Roma decretou "que todos os recém-nascidos - até a idade de três anos - que constituíam um peso potencial para o Estado, podiam ser sacrificados" (SKLIAR apud PERLIN, 2002, p.27). Ou seja, o povo surdo passou de uma população protegida pela benevolência para um fardo pesado e desnecessário para o Estado, devendo ser descartado, tão logo quanto se identificasse o defeito, pois neste período da história o sujeito surdo passa a ser identificado como deficiente físico por possuir uma parte de seu corpo que não funciona como o esperado. Nesta época vê-se uma primeira passagem em relação à população surda: de infelizes segmentos da sociedade protegidos por benevolentes, a infames malditos 
que devem ser retirados de circulação. Neste momento histórico, a deficiência física era entendida como um castigo dos deuses, o que tornava tais pessoas merecedoras de descaso, pois os deuses só castigam aqueles que não são suficientemente bons. Foi neste período, também, que surgiu, a partir de Aristóteles, a relação entre surdez e mudez que confirmou a impossibilidade destas pessoas participarem socialmente, uma vez que não tinham como se comunicar.

A história começa a tomar novos rumos quando, no primeiro século depois de Cristo, o neto do imperador Cesar Augusto nasce surdo, então é dada a ele a possibilidade de cultivar, aprimorar e exercer suas habilidades artísticas, porém tal possibilidade é extremamente limitada, pois não se estende à área científica, onde os surdos continuam sendo vistos como incapazes. No século VI d.C., houve o primeiro reconhecimento legal do sujeito surdo onde, a partir do Del Postulare, constante no Código Justiniano ${ }^{\text {ii }}$, surge uma lei quanto à capacidade de uma pessoa expor em juízo o próprio desejo ou de outrem e de poder contradizê-lo. Este documento divide as pessoas em três categorias distintas: as que não podem postular por si mesmas; as que podem postular por si; e as que podem postular por si e pelos outros. Neste código os surdos estão inseridos na primeira categoria, e passam a ter sua deficiência distanciada das demais, pois volta-se a diferenciar surdez e mudez, abrindo novas possibilidades de socialização para estas pessoas. A partir do século XIV os "Mestres de Surdos" passam a se sobressair na história da aprendizagem, tendo seus métodos de entendimento e ensinamento registrados, dos quais alguns perduram até os dias atuais. Eis aqui uma segunda passagem quanto à surdez: de infames a deficientes. Um primeiro movimento da história que vem marcar a população surda no âmbito da "falta"; característica que, mais adiante, a ciência psicológica captura como passível de intervenção de suas práticas.

A partir deste momento começa a ficar evidente o funcionamento dessa nova racionalidade, da governamentalidade, pois é no contato com estes mestres que os surdos começam a efetivamente ser vistos e capturados por sistemas universalizantes de linguagem, o que possibilita, também, o acesso deles aos padrões comportamentais, cognitivos, e subjetivantes advindos das manifestações do poder exercidos na época. E é na educação que a maestria da surdez encontra sua legitimidade. Como exemplo dos precursores neste campo, temos Girolamo Acquapendente, professor de Anatomia da Universidade de Pádua no início de 1700, que diferenciou os sinais utilizados pelos surdos para sua comunicação, de pantomimas e expressou um novo pensamento sobre as dificuldades de comunicação com esta população, dizendo: "eles são considerados incapazes de se expressar somente porque ninguém os pode compreender". Já a primeira escola pública para surdos foi fundada no ano de 1760 em Paris por Abade L'Epée. L'Epée iniciou seu trabalho com surdos com aproximadamente 60 anos 
aprendendo a Língua de Sinais com os surdos pobres de Paris; o mesmo inseriu a Língua de Sinais no ensino de surdos, criando uma escola específica para eles e utilizando seu método de ensino que ficou conhecido como Sistema de Signos Metódicos. Com isso L'Epée inaugurou um novo período na história da surdez, onde os indivíduos surdos passam a ter a possibilidade de ser ouvidos. Entretanto, vale ressaltar que esta escuta surgia a partir de ideários normalizadores, ou seja, do surgimento de uma necessidade de educar tal população.

O advento da Língua de Sinais foi aceito por pouco tempo, pois no século XIX ciências como a Medicina e a Filosofia passam a contestar a diferenciação dos métodos de ensino das pessoas surdas e das ouvintes, abafando assim a utilização dessa linguagem específica e impondo ao sujeito surdo o valor da palavra falada e da normalidade ouvinte, iniciando um processo de oralização destes sujeitos, uma vez que o método específico de ensino anteriormente utilizado foi considerado inadequado ao desenvolvimento humano. O sistema de ensino baseado na oralização é produto de um entendimento da surdez baseado na patologia, considerando-a como uma doença crônica, o que constitui um processo de subjetivação dos surdos enquanto sujeitos "doentes" modificando mais uma vez as normas nas quais eles devem se fazer caber. Samuel Heinicke, médico alemão considerado o fundador do oralismo, entendia que a surdez é decorrente de uma "lesão no canal auditivo que obstaculiza a aquisição da língua" oral, então iniciou um trabalho baseado em intervenções clínicas capazes de corrigir o erro e induzir o sujeito surdo à fala. Tal método continua sendo utilizado para a educação da pessoa surda nos dias atuais, pois tende a adequar o não ouvinte ou modo de vida e relacionamento social do ouvinte, mantendo uma relação de poder entre dominante e dominado.

\begin{abstract}
"O fato é que a comunidade surda foi posta para fora [da sociedade] e isolada, porque insistia em manter a língua de sinais que facilitava a comunicação em todos os sentidos. O motivo pelo qual a comunidade surda insistia tão enfaticamente em manter a língua de sinais poderia ser devido a um respeito profundo por uma força criadora interior da natureza humana e social. Essa força criadora possibilitou à comunidade surda descobrir uma linguagem realmente funcional e boa - a língua de sinais - que facilitava seu desenvolvimento, apesar de todas as investidas contra ela" (WIDEL, 1992 apud PERLIN, 2002, p. 51).
\end{abstract}

Tal movimento convoca a uma terceira passagem quanto à surdez: da deficiência para um grupo especial, que merece atenção e cuidados próprios; seja sob o cunho do déficit, seja para sua adequação e docilização. Sob tal ótica, ao olhar para a construção histórica da surdez, é possível ver o quanto esta é tomada sob o viés moralista da distinção entre o perfeito e o imperfeito. O mais importante destas passagens na história da surdez - desde uma condição marcada tanto pela assistência quanto pela infâmia e, após, pela deficiência - é compreender o quanto são produzidas especificidades sobre a população surda, recaindo sobre ela toda uma 
gama de saberes e poderes que vêm conduzir o surdo como aquele que deve se adaptar, se incluir, se esforçar para engendrar-se nas normas. Eis o ponto em que a surdez passa a ser incorporada às Políticas Públicas de Inclusão: quando o Estado passa a se preocupar com sua inclusão e a Psicologia passa a ser um dos saberes que vem ditar sua normalidade.

\section{O estado, as políticas de deficiência e a inclusão social}

Após compreendermos os movimentos acerca da visão da surdez nos caminhos da história, torna-se necessário transcorrer a discussão para como, na sociedade contemporânea, o movimento governamental possibilita a criação e mantimento de práticas de inclusão da população surda. Ao atentarmos para certas condições sócio-históricas de meados do século XX, é possível identificar um processo de responsabilização do Estado com a promoção de saúde das pessoas com deficiência no Brasil. Isso ocorre com a emergência de necessidades sociais de regulação e controle dos corpos em prol de uma normalidade hegemônica, sobre as quais a população surda passa a ser tomada como um público-alvo em relação a seus cuidados, sua proteção e, juntamente a isso, seus direitos e diretrizes. Temos, na luta de classes, na retomada da democracia pós-golpe militar e na criação da Constituição da República Federativa do Brasil de 1988, alguns dos processos históricos que passam a produzir uma subjetividade "especial" em relação àqueles tomados como "deficientes", sob os quais se vê uma quarta compreensão à visão da população surda: de uma condição de incapacidade a um reconhecimento de direitos. Eis que tais direitos, entretanto, somente são conquistados a partir do lugar "especial" da deficiência. Sob esse ponto de vista, considera-se o artigo 23 da constituição o qual determina que "é competência comum da União, Estados, Distrito Federal e Municípios, cuidar da saúde e assistência públicas, da proteção e garantia das pessoas portadoras de deficiência" (BRASIL, 2010b, p. 01). Para a Classificação Internacional das Deficiências, Atividades e Participação o conceito de deficiência inclui a participação social como uma "interação que se estabelece entre a pessoa portadora de deficiência, a limitação da atividade e os fatores do contexto socioambiental". Nesses termos, compreende-se que o conceito de inclusão social surge estabelecendo uma articulação entre a necessidade de adaptação da pessoa com deficiência e uma obrigação da sociedade em tolerar esse outro diferente, visando minimizar a relação inerente a condições socioambientais desiguais.

Para tais dispostos se tornarem efetivos deve haver uma modificação da estrutura relacional entre Estado, sociedade e indivíduo, priorizando o respeito e o acesso à cidadania e aos direitos sociais, para, então, possibilitar o atendimento das necessidades de todos os membros 
da sociedade, inclusive dos que anteriormente eram considerados excluídos. Ao mesmo tempo em que tal ação passa a propor práticas igualitárias a todos, sem estereotipar a população surda, passa a conjugar uma homogeneização das diferenças. Desta forma, as normas estabelecidas a partir desse momento determinam que o Estado estabeleça estratégias de ação que possibilitem às pessoas surdas o acesso aos mesmos ambientes socioculturais destinados à população geral, visando, assim, manter o povo surdo sob seus olhos e submetê-los a seus padrões normalizantes que começam a ditar como ser surdo. As políticas inclusivas, assim, colocam-se como estratégias de governamentalidade não somente da população surda, mas como de toda a sociedade ouvinte, pois vêm ditar regras de convivência e aproximação entre aqueles considerados normais e os diferentes que devem ser incluídos.

Este processo de possibilitar o atendimento das necessidades de todos os cidadãos nada mais é que o princípio de equidade de que nos fala o Sistema Único de Saúde (SUS), ou seja, de ofertar atendimento diferenciado às pessoas diferentes, o que significa aceitar a diferença e saber conviver com ela, sem estereotipá-la nem desconsiderá-la, tornando possível o acesso destas pessoas "aos serviços públicos, aos bens culturais e aos produtos decorrentes do avanço social, político, econômico e tecnológico" (BRASIL, 2010b, p. 02) disponíveis. Contudo, tal quadro é contraditório, uma vez que a falta de atenção às pessoas com deficiência ainda é reflexo da maneira como o assunto foi introduzido na relação de cuidado do Estado para com os "deficientes". Este cuidado surgiu como atendimento elementar em apenas duas áreas de atuação, a educação e a saúde, e eram responsabilidade de instituições filantrópicas, que ainda hoje são referência em atendimento específico a esta população. Posteriormente, o cuidado foi integrado a atendimentos de reabilitação, mantendo o caráter assistencialista, paternalista, excludente e a atenção seccionada, excluindo a integralidade do sujeito, sua autonomia e dignidade enquanto sujeito de direitos. Assim, vários saberes e certa expertise são convocados para "pensar sobre" e "atuar com" tais grupos, garantindo e facilitando seus direitos. A Psicologia, assim, aparece neste ponto para atender a população surda - apesar de ser depois da fonoaudiologia e da pedagogia - como uma prática que vem trabalhar na "inclusão" deste outro.

É neste ponto contraditório que também a Psicologia aparece para nortear os trabalhos desenvolvidos com a população surda. Esta ciência inicialmente surge identificando e qualificando os "anormais"; convocada por meio de ações que trazem o lema da proteção e cuidado à diferença, as práticas psicológicas surgem em meio a essa política de governo neoliberal agindo sobre os sujeitos surdos visando a entender suas identidades, capacitar suas faltas e ajudar na promoção da sua tolerância. Cruamente, pode-se dizer que a Psicologia, enquanto 
ciência implicada pós-ditadura na luta pela promoção de saúde, também passa a fazer parte de um jogo político de regulamentação da diferença. Na conquista pela inclusão de pessoas com deficiências, temos na implementação da Política Nacional de Saúde da Pessoa Portadora de Deficiência (PNSPPD), as diretrizes norteadoras sobre a atenção e o cuidado com as pessoas com deficiência, sendo elas:

\footnotetext{
"promoção da qualidade de vida das pessoas portadoras de deficiência; assistência integral à saúde da pessoa portadora de deficiência; prevenção de deficiências; ampliação e fortalecimento dos mecanismos de informação; organização e funcionamento dos serviços de atenção à pessoa portadora de deficiência; e capacitação de recursos humanos" (BRASIL, 2010b, p. 10).
}

Ainda que certas naturalizações sobre a população surda sejam produzidas pelas políticas para pessoas com deficiência, elas também nos mostram que muito vem sendo elaborado visando o melhor atendimento e acompanhamento desta população. Contudo, um dos fatores apontados nos movimentos de luta pela inclusão é a falta de recursos humanos especializados, principalmente quando se fala em atendimentos específicos ao surdo, pois este exige do cuidador a aprendizagem de uma língua estrangeira. Visando possibilitar ao deficiente, conforme colocado nas políticas anteriormente mencionadas, um lugar de protagonismo político, determinou-se que os espaços públicos e a acessibilidade ao meio físico, à comunicação e à informação devessem garantir a todos os cidadãos a oportunidade de usufruir adequadamente de seus direitos.

Sendo assim, algumas medidas foram tomadas a partir da criação de leis e decretos assegurando os direitos da pessoa com deficiência. Este movimento iniciou na década de 1960 com ativistas e organizações de pessoas com deficiência que buscavam seus direitos e acabaram chamando atenção para a importância de se pensar nesta parcela da população. A partir desta data iniciou-se, também, um processo de modificação no entendimento da deficiência, transferindo a culpabilidade do sujeito para o meio, onde passou a ser vista "como produto das barreiras físicas, organizacionais e atitudinais" (BRASIL, 2012, p. 16-17). Na década de 1980, com a implementação da Constituição Federal, a saúde passa a ser definida como um dever do Estado e um direito de todo cidadão, independente de sua condição, garantindo "o acesso universal e igualitário às ações e serviços” (BRASIL, 2012, p.17) dessa natureza. Ainda nesta época foi criada a Coordenadoria Nacional para a Integração da Pessoa Portadora de Deficiência (CORDE) com a tarefa de "elaborar planos, programas e projetos, voltados para a implementação da Política Nacional para a Integração das Pessoas Portadoras de Deficiência" (BRASIL, 2012, p. 18), contudo a CORDE só foi instituída na prática na década seguinte e atualmente possui o status de Secretaria Nacional. No final da década de 1990 foi estabeleci- 
do mais um órgão na luta por direitos da pessoa com deficiência, o Conselho Nacional dos Direitos da Pessoa Portadora de Deficiência (CONADE) com a função de zelar pela efetivação dos direitos desta população.

Ao final do século XX criam-se a Lei Federal no 10.048 e a Lei ${ }^{\circ} 10.098$ que discorrem sobre a questão de acessibilidade para as pessoas com deficiência, estipulando que elas devem ter assegurados os direitos à acessibilidade ao meio físico, ao transporte, à comunicação, à informação e a ajudas técnicas, ou seja, é preciso que se tenha recursos humanos devidamente preparados para atender todos de maneira integral, humana e adequada. Vindo ao encontro destas determinações, é editada no início do século XXI, a Lei no 10.436 que regulamenta sobre a Língua Brasileira de Sinais (Libras), considerando-a como uma forma de comunicação e expressão com sistema linguístico próprio para a transmissão de ideias e fatos e estabelecendo, em seu artigo $3^{\circ}$, a responsabilidade de serviços públicos de saúde garantirem ao surdo um atendimento e tratamento adequado, o que significa que, para garantir o cumprimento do disposto na lei, deve haver pessoas habilitadas para o uso da Libras tanto em ambientes destinados a saúde, como nos espaços públicos em geral. Em relação a este aspecto, Camatti e Gomes (2011), adiantam que, apesar de ser um avanço, essa conquista também produz um reducionismo e uma captura da cultura surda, transformando a potência da Língua de Sinais em uma racionalidade metodológica ou ainda, simplesmente tomada como mais um recurso adaptativo a ser aprendido.

As mesmas autoras ainda nos convocam a pensar sobre o discurso retórico da diferença na contemporaneidade. Conforme mencionado anteriormente, a partir da conquista de um lugar de sujeito de direitos, a população surda passa a ser convocada a um lugar de protagonismo e luta de garantias, contudo, tal processo ocorre pelo reconhecimento da diferença como principal argumento para sustentar reivindicações. Neste cenário, passa a existir um apelo à/da diferença, uma ordem discursiva que produz marcas identitárias que vêm conduzir o sujeito surdo, ainda que sujeito de direitos, como aquele suspenso na fronteira entre o normal e o anormal. Isso pode ser visibilizado nas modificações nominais nas políticas de inclusão. Com o advento de tantas modificações no paradigma de entendimento e convivência com pessoas com deficiência, a terminologia utilizada para se referir a tais pessoas sofre alterações, sendo, atualmente, utilizada a terminologia Pessoa com Deficiência, pois tal denominação busca tirar a deficiência do centro de atenção, colocando a pessoa em primeiro plano, tendendo a minimizar o estranhamento e o estigma vivenciados por elas, abrindo assim, novas formas de relacionamento com a sociedade e os serviços de atendimento específico, tornando a sociedade parte integrante do sistema de inclusão. Tensionando esta nomenclatura, contudo, 
torna-se importante colocar que a priori mantém-se estabelecido o lugar do déficit, da falta, da marca de certa "degenerescência" que vem provocar a entrada em um sistema de direitos das garantias e inclusões - a partir da deficiência. Ainda que a "pessoa" fique em primeiro plano, ela vem amarrada "com deficiência". Neste sentido, quando as legislações que preconizam o direito desse grupo populacional surgem, elas o fazem legitimando e normatizando a intervenção sobre estes seres deficientes. Como Camatti e Gomes (2011, p.173) provocam: “a diferença surda, nesse jogo, parece cair em uma luta inglória, já que, colocada nessa esfera, estará sempre em relação à condição ouvinte".

Dessa forma, enquanto há a manutenção da lógica deficitária, binária sobre o sujeito surdo, as relações de cuidado e proteção que as políticas inclusivas vêm propor conjugam-se enquanto estratégias de governamentalidade sobre este grupo populacional. E eis a grande questão para a Psicologia! Pois, enquanto esta ciência estiver amarrada com heranças pedagógicas, disciplinares e de maestria da subjetividade humana, suas práticas passam a ser um dispositivo de gerenciamento da normalidade, regulamentando quais sujeitos são passíveis de inclusão. Surge aí uma amarra nevrálgica entre Psicologia, surdez e inclusão; diz-se nevrálgica, pois convoca-se nessa parceria todo um aparato do governo e gestão do diferente.

\section{A surdez (des)coberta pela psicologia}

A Psicologia começou a aproximar-se da pessoa surda na década de 1950, quando a psicometria começou a ser desenvolvida e foi utilizada para mensurar a capacidade cognitiva dos surdos, porém os instrumentos utilizados para este fim foram desenvolvidos para mensurar tal capacidade em pessoas ouvintes, concluindo-se com isso que pessoas surdas eram intelectualmente inferiores às pessoas ouvintes (SOLÉ, 2005). Em 1960, com a "psicologia da surdez", se "mantém uma visão clínico-terapêutica educativa da surdez que implica o pensamento de que a surdez invariavelmente produz, independente do grau de perda, transformações negativas no desenvolvimento da criança surda" (SOLÉ, 2005, p. 31), o que reflete a construção histórica engendrada por discursos ouvintistas de que a surdez é, a priori, incapacitante. Tanto é que, a própria terminologia "discurso ouvintista", é convocada por Sklier (apud STRÖBEL, 2007, p.19) para determinar o conjunto de representações ouvintes que são utilizadas para determinar formas de ser surdo, subjetivando e governando a diferença. Assim, tal entendimento estabelece uma forma de cuidado baseada e interessada em proporcionar aos surdos um diagnóstico - fundamentado nas formas normatizantes de lidar com a diferença - e sua reabilitação - colocando em prática a normalização das mesmas. 
Porém, atualmente, estudos (BISOL, SIMIONI e SPERB, 2008) realizados sobre produções científicas de profissionais da Psicologia demonstram que a concepção desta área de atuação sobre as pessoas surdas está mudando consideravelmente, pois ao contrário do modelo anterior, que mantinha uma visão clínico-terapêutica da surdez, a concepção atual está mais voltada para o entendimento socioantropológico, que considera a pessoa surda como integrante de uma cultura distinta e com uma forma linguística diferenciada da maioria populacional, o que interfere diretamente na maneira como se compreende tal público e como relacionar-se com ele, distanciando-se da busca diagnóstica e reabilitadora. Em vez de deficiência, entendese a surdez como diferença.

Com a mudança de entendimento por parte da Psicologia quanto às pessoas surdas, entende-se que surge, então, uma nova possibilidade de atuação em que o surdo seja distanciado da noção de déficit, e passe a existir no mundo de uma forma muito mais voltada a suas experiências e potencialidades experimentais do que apenas reproduzindo a "subjetividade deficiente" com a qual foi ensinado a viver. Uma vez quebrada a relação histórica entre falta de audição e deficiência, abre-se espaço para o surgimento de novas formas de existência sem a audição (MORAES, LIMA e MANSOIO, 2011). Produzindo outros caminhos distintos dos percorridos até os dias atuais pelo governamento dos corpos - visando à disciplina e a punição do deficiente, do inválido - estas novas possibilidades de ser surdo autorizam estas pessoas em sua autonomia e busca de sentido.

Porém, para alguns teóricos, o atendimento feito por um profissional cuja língua materna seja diferente da de seu paciente está, a priori, incapacitado para compreender e identificar a subjetividade daquele que o procura em busca de saúde. Mas como Solé (2005) nos exemplifica, a dificuldade de realizar um atendimento psicoterápico em que o profissional não compreende a língua de seu cliente é comparável ao atendimento a clientes estrangeiros, cuja língua materna distingue da língua utilizada pelo profissional que o atende.

\footnotetext{
"Nesses casos, é possível perceber com o andamento da análise que a língua da infância vai surgindo. Os atos falhos acabam sendo cometidos na língua materna: há sobreposição das duas línguas (materna e estrangeira adquirida em seu novo país) ou esquecimento da tradução ou o analisante esquece a palavra ora em português, ora em espanhol. Isso seguramente não impediu que se desse uma análise, mas sempre é necessário que o analista esteja atento para a escuta dessa outra língua imiscuída no discurso, pois nela sempre está uma manifestação do inconsciente. [...] $\mathbf{O}$ analista, incapaz de decodificar as palavras de seu analisante [...] estará trabalhando no nível da imagem e da suposição do que a imagem quer dizer" (SOLÉ, 2005, p. 82-87, grifos das autoras).
}

Ao grifar tais partes da citação acima, questiona-se a necessidade de se priorizar a fala como elemento fundamental do encontro bipessoal (entre psicólogo e cliente), uma vez que a 
clínica psicológica faz uso de muitas ferramentas além da palavra. Entende-se que tais ferramentas sempre estiveram (e talvez ainda estejam) pautadas no entendimento e parâmetro ouvintes, e que isso inviabiliza a utilização de tais métodos a outra população que não a já conhecida e estudada, e que, igualmente, há suspeitas de que tanto o desenvolvimento quanto as expressões psíquicas e emocionais seriam diferentes nos sujeitos surdos, o que possibilita refletir sobre o papel que a Psicologia está exercendo quando se dispõe a atuar sob este entendimento: ao fazer isso estarão sendo reproduzidas formas de subjetivação deficientes ou se estará possibilitando a construção de mecanismos desestabilizadores dos entendimentos, já instituídos, de surdez? Apesar de intrigante e desafiador este assunto não foi (e ainda não é) muito estudado, principalmente no Brasil, apesar de alguns autores de peso para a Psicologia, como Freud e Lacan, terem citado em suas obras a existência das pessoas surdas, nenhum deles se deteve em imaginar, nem compreender como seria a clínica psicológica com estes sujeitos.

Para melhor compreender o caminho percorrido e o entendimento de surdez que perpassa pela Psicologia, destacar-se-á trechos de discursos de alguns profissionais da área sobre esta população para analisar, tomando como ferramenta a governamentalidade. Desse ponto de vista, a ideia é problematizar tais narrativas a fim de pensar que racionalidades passam a emergir nos discursos psicológicos ao se referirem a certo modo de atender, olhar e escutar esta população. Assim, trazem-se, a seguir, depoimentos de entrevistas, recortes de websites e trechos de livros que abordem a temática: práticas psicológicas e surdez ou psicologia e a diferença surda.

A seleção e convocação para agrupar tais materiais deve-se, primeiramente, a um exercício de mapeamento de alguns discursos presentes no campo das práticas psicológicas a fim de tensioná-los buscando responder: como a Psicologia vem tomando a surdez? Assim, ao trazer tais discursos, pensa-se em como eles propõem determinadas práticas sobre/com o outro. Nesses termos, a análise das práticas não está no nível de algo oculto ou explícito, mas daquilo que as organizam como sistemas de ações. "A prática não é uma instância misteriosa, um subsolo da história, é o que fazem as pessoas (a palavra significa exatamente o que diz)" (VEYNE, 1982, p.157-158). Assim, o foco investigativo encontra-se na própria concretude das práticas em sua capacidade de produzir subjetividades. Ao trazer o que os psicólogos vêm falando sobre a surdez, compreende-se que estas narrativas constituem modos de ser sujeitosurdo na contemporaneidade. Tampouco, vale ressaltar, a ideia é partir de uma crítica pela crítica, mas pensar rupturas com o viés da deficiência e/ou da diferença subjugada, que visa 
ser normalizada; a proposta, assim, se insere, em pensar possíveis, outras formas de trabalhar e escutar a surdez que provoquem uma postura ética na relação com o outro.

Sendo assim, apresentam-se alguns discursos encontrados no decorrer desta escrita, bem como outros adquiridos a partir de pesquisa prévia e agrupados em diário de campo. Eles foram divididos em três possibilidades de tomar as práticas psicológicas e a surdez: $1^{\mathrm{a}}$, a clínica enquanto uma ciência que toma a surdez como deficiência, que vem para "ajudar" à adaptação; 2a a clínica enquanto uma ciência que deve aprender a língua "deles", que vem convocar aos psicoterapeutas e demais psicólogos a compreender e empatizar com as necessidades especiais da pessoa surda; e $3^{\text {a }}$, a clínica como um espaço potencial de relação entre pessoas. Para iniciar este movimento analítico, seguem os seguintes trechos abaixo:

\footnotetext{
A questão da surdez nada mais é do que uma problemática política de defesa de saberes. Esta discussão é muito mais uma disputa de saberes e verdades dos ouvintes do que um posicionamento preocupado com as necessidades das pessoas surdas. (LABORIT, 1992, apud SOLÉ, 2005, p.20, grifos das autoras).

Uma das grandes dificuldades do surdo é lidar com suas emoções e tos. Não porque seja diferente dos ouvintes, que vivem os mesmos conflitos e angústias, mas pela inexistência de um sistema de atendimento psicológico que contemple suas necessidades e peculiaridades. (GONÇALVES, 2013, s/p., grifos das autoras).
}

Ao considerar o interesse pelas pessoas surdas como sendo uma disputa de saberes ouvintes, Laborit (1992, apud SOLÉ, 2005) se remete ao movimento, já mencionado, de normalização da diferença a partir de conhecimentos ouvintistas que pretendem determinar como é ser surdo, despotencializando o discurso dos próprios surdos sobre suas reais necessidades. Também o segundo recorte mostra a fragilidade do acesso ao encontro psicoterápico, quando este não possibilita que o cliente estabeleça suas necessidades e peculiaridades, pois o toma como incapaz de realizar tal julgamento. Com isso entende-se que a pessoa surda necessita muito mais de uma relação humana de igualdade, do que uma relação pautada em saberes preconcebidos sobre as pessoas. Quando surge a preocupação em conhecer e estabelecer saberes sobre determinados grupos sociais, há a produção de certa necessidade de incorporar tais grupos aos moldes de governamento estabelecidos, fazendo com que se tornem eficientes para as necessidades da época em questão, ou seja, em determinado período histórico, os "diferentes" eram excluídos da sociedade por serem considerados incapazes de realizar funções trabalhistas tão importantes na época. Hoje, porém, vive-se a necessidade de controle e entendimento universais instituídos pelas "habilidades" de comunicação e integração da diferença, uma vez que tais entendimentos são absorvidos pelas políticas de gestão da sociedade, onde se estabelece a necessidade de haver profissionais e instituições especializadas na diferença. 
Têm-se nos recortes acima, a produção da clínica da adaptação, da falta e do déficit e, a seguir, trechos em que se tem visibilidade de uma clínica especial. Nesta, o outro surge como um estrangeiro ao qual se tem curiosidade de conhecer, de entender: como um povo ou terra estranha a serem desbravados.

\footnotetext{
Por saber da demanda e da dificuldade em encontrar profissionais especializados em atendimento para surdos e que tenham conhecimento da Libras, venho me apresentar e me colocar a disposição para maiores informações, pois também sou psicóloga e atendo surdos com Libras". (Psicóloga em comentários, COSTA, 2011, s/p., grifos das autoras)

O psicólogo que deseja trabalhar com surdos deve primeiramente entender que essa é uma área de grande demanda. No entanto a quase totalidade dos surdos nunca teve acesso à psicoterapia, [...] simplesmente porque o poder público não oferece esse tipo de atendimento e quando oferece, é precário e sem profissionais habilitados e capacitados para essa especialidade. Até mesmo porque não existem cursos de capacitação para terapeutas de surdos. Desse modo, é muito difícil encontrar profissionais em todo o país que se dediquem a essa prática. (GONÇALVES, 2013, s/p., grifos das autoras).
}

Os recortes acima descritos mostram a compreensão de alguns profissionais da Psicologia de que só é possível corresponder à demanda dos surdos com a especialização, onde o conhecimento da Libras é fundamental. Entende-se que é importante estabelecer uma forma de comunicação entre duas ou mais pessoas, contudo compreende-se, também, que a comunicação não está pautada apenas na linguagem falada. Resumir a interação e a possibilidade de atuação profissional apenas a especialidades linguísticas é subjugar a relação humana, tomando, a priori, uma das partes como incompleta, o que torna a própria relação deficitária, partindo de uma compreensão reducionista sobre o outro. Assim, é possível perceber que a necessidade de especialização, que parece contrariar a noção de déficit, indo ao encontro da inclusão do diferente, está, também, calcada no movimento de normalização. Ao estabelecer que a Libras é a língua dos surdos, restringe-se a esta população uma única possibilidade de comunicação, que passa a ser vista somente como uma ferramenta metodológica e recursiva, o que inviabiliza muitas atuações profissionais e pessoais.

Dito de outra forma, determinar que um profissional só está habilitado a atuar com um grupo específico quando possui total conhecimento sobre o "seu" mundo, a "sua" língua e as "suas" especificidades, mantém o relacionamento dicotômico entre sujeito-objeto, em que há distanciamento entre um e outro. Assim, retira-se da Psicologia uma das suas mais potentes formas de atuação, a relação interpessoal, uma vez que o sujeito-cliente é tomado como objeto deficitário e incapaz de estabelecer tal interação. Com isso, pergunta-se: especializar ciências é realmente incluir? Especializar saberes é realmente conhecer? Falar em nome de alguém 
corresponde a dar-lhe voz? Se a especialização for realmente o único caminho possível, como serão atendidos os surdos não conhecedores de Libras?

Neste sentido, salienta-se que não se promove nesta escrita uma postura contra a adequação curricular da Psicologia para a inserção de disciplinas de Libras, mas se questiona essa como sendo a única forma possível de pensar a clínica com tal população. Desse modo, trazse a noção de clínica aqui com um viés descolado do olhar bipessoal e/ou individual, mas a clínica enquanto terapêutica da relação.

\footnotetext{
Penso que o trabalho da Psicologia referente aos surdos deve ser de empoderálos enquanto sujeitos ativos de suas histórias, facilitando suas circulações pelo meio, uma vez que este também deve ser trabalhado para a aceitação e independização do sujeito." (Psicóloga em resposta a pesquisa anônima realizada por e-mail, grifos das autoras).

Quando chegou a hora de decidir o que eu queria para a minha vida, não pensei duas vezes: Psicologia. Sempre fui boa ouvinte, o que é bem irônico. [...] Sou surda, sim, mas graças a ela, tenho um raciocínio rápido, sou boa observadora, consigo perceber coisas e detectar sinais." (BATISTA, 2013, s/p, grifos das autoras).
}

Por meio dos recortes acima, é evidenciada não só a possibilidade de um terceiro viés, diferentemente dos anteriores que predeterminam o sujeito como deficiente ou "especial". As práticas psicológicas aí convocadas mostram que a questão não é a diferença entre surdos e ouvintes e sim a similaridade entre pessoas. Esta forma de perceber o outro como sendo "apenas" um outro, sem nenhum adjetivo composto a ele, como o "outro deficiente" ou o "outro diferente" ou, ainda, o "outro especial", está pautada no respeito antes de afirmar-se como “saber". É este novo lugar, onde não há necessariamente uma especialidade, a priori, sobre o outro que se apresenta, que existe a potência do encontro com uma outra Psicologia. É importante ressaltar, que não se está desconsiderando as especializações e, tampouco minimizandoas; a proposta, aqui, é que elas não fiquem em primeiro plano quando se pensa em "Psicologia para surdos". Arrisca-se questionar, inclusive, a existência de uma ciência e saberes específicos para surdos, provocando um trabalho que venha problematizar práticas e produzir uma virada: para além de uma visão clínico-terapêutica ou socioantropológica, mas uma relação ético-política. Certamente, a questão que pulsiona é aquela que cabe no espaço das utopias: será possível essa outra maneira de ver, sentir e ouvir tal população?

A resposta não é certeira, e coloca-se à mesa mais como um processo de desassossego, principalmente quanto à pretensão da Psicologia com suas ferramentas de entendimento, possibilidades de explicações ou mesmo suas formas ouvintes (e de não-ouvir). Uma aliança, neste momento, com Moraes (2010, p.16), quando esta nos convida a uma ciência política com o outro, e não sobre ele. Isto significa tensionar também a idealização de uma lógica 
ideal, mas exercitar a capacidade crítica das práticas psicológicas, convocando-as a transcorrerem no espaço do entre, contra essencializações sobre o sujeito surdo. Uma outra escuta, que reside na "possibilidade de uma psicologia cujas intervenções estivessem no espaço do 'e', construindo uma relação aditiva, que se produzisse a partir da interseção, levando em conta o referencial do outro".

\section{Para perpetuar o entusiasmo: uma terceira margem}

Talvez incida-se aí a proposição deste artigo: pensar novas possibilidades do encontro da Psicologia com a surdez, diferentemente da noção de "Pessoa com Deficiência Auditiva", buscando autores e profissionais que entendem que há outras formas de existência pautadas no sentido de existir e não na ausência de audição. Sendo assim, por que afinal, a escolha por enfatizar as diferenças pessoais em vez das similaridades? Ao considerar que não existem, no mundo, duas pessoas totalmente iguais, é desnecessário basear nossas interações naquilo que nos diferencia, procurando sempre estabelecer saber científico para determinar uma vontade/possibilidade de atuação profissional. Nesses termos, a proposta aqui também incide sobre um exercício que busca desnaturalizar (e retirar de uma condição de banalidade) o discurso da diferença.

Durante a redação do presente artigo, foram levantados alguns questionamentos, tais como: é possível a atuação da Psicologia com pessoas surdas? A partir de que lugar esta ciência toma este público-alvo? Será possível uma atuação profissional que destitua o surdo do lugar de deficiente? Será utopia acreditar que há outra maneira de ver, sentir e ouvir tal população? Muito foi pesquisado e analisado a partir de dispositivos emprestados de Foucault, o que possibilitou compreender o caminho percorrido até os entendimentos atuais de deficiência, inclusão, acessibilidade e subjetivação. Porém, como era de se esperar, nem todas as perguntas foram respondidas, ao que parece, mais perguntas surgiram, mas se, ainda assim, foi possível ampliar a visão, o entendimento e o raciocínio no que tange a produção de conhecimento em relação a esta temática, considera-se um primeiro passo.

Este primeiro passo pode ser entendido como uma inquietação e desnaturalização das práticas envolvidas nos mecanismos de inclusão e interação entre o profissional e seu cliente. Permitir-se perceber, criar e proporcionar um novo espaço, nos entremeios do que já está preestabelecido como norma de atuação. Assim, entende-se que pensar novos possíveis abre espaço para o estabelecimento de outro viés perceptivo, possibilitando formas de interação distintas, fundamentadas na humanidade e na empatia. Compreender que há mais de dois pontos 
de vista, além do contrário e do favorável, possibilita visualizar um terceiro espaço onde outras formas de ser, perceber, sentir e relacionar-se predominem.

Quando falamos em compreender que é possível estabelecer uma nova perspectiva de atuação com pessoas ditas impossibilitadas de comunicação, estamos nos referindo àquilo que já é conhecido em algumas teorias psicológicas como "encontro", locupleto de contato, linguagens corporais, presença e vontade de comunicação. Neste sentido acreditamos não ser utópica a esperança e o desejo da existência de um espaço onde tal encontro seja possibilitado pela união de conhecimento teórico, prática e sensibilidades das práticas psicológicas. Porém ao incitarmos a necessidade de implantação de um espaço específico para pessoas surdas, questionamo-nos novamente sobre os processos de inclusão, principalmente quando estes convocam-se sob racionalidades de gestão da diferença, perpetuando as lógicas binárias e seccionadas.

Em "A terceira margem do rio", Guimarães Rosa exemplifica a existência de um espaço entremeios, onde o que predomina não são as certezas, mas as sensações e relações existentes neste novo espaço. Mais do que demonstrar a existência deste possível, Rosa (1988) expõe a vontade de permanência neste espaço distanciado de necessidades afirmativas e especialistas quando afirma: "só executava a invenção de se permanecer naqueles espaços do rio, de meio a meio, sempre dentro da canoa, para dela não saltar, nunca mais” (ROSA, 1988, p. 32). Do mesmo modo, compreende-se a existência e importância das margens já instituídas, porém hospeda-se, nesse exercício de inquietação, a vontade de habitar a terceira margem possível, principalmente quando esta margem está intimamente ligada a atuação profissional com públicos-alvos historicamente excluídos e muitas vezes compreendidos como frágeis e deficitários. Sendo assim, deseja-se apenas que as práticas psicológicas se "depositem também numa canoinha de nada, nessa água que não para, de longas beiras: e, elas, rio abaixo, rio a fora, rio a dentro - o rio" (ROSA, 1988, p. 32 - adaptação).

\title{
PSYCHOLOGY AND DEAFNESS: GOVERNMENT OF DIFFERENCE AND OTHER POSSIBLE MARGINS
}

\begin{abstract}
In a time in which Inclusion of the Disabled and the necessity of preparation for the practicing of this inclusion is discussed, the present article intends to state historically in what moment deafness begins to be understood as a disability, incorporated to the Public Politics of Inclusion through a production of its specificity and scientific knowledge. In this sense, the present paper intends to problematize the moment and way deaf people become a target for the Psy-
\end{abstract}


chology. Throughout the discussion, the understanding of the rule and normalization moves and governing of the difference is proposed, aiming to present the possibility and/or the need of launching a new look upon deafness with the goal of changing the relationship between Psychology and Deafness, differently from the knowledge-object relationship in which such encounter is instituted. In order to do so, some statements and talks present in the speeches of professionals of the field will be tensioned identifying what place Psychology speaks from currently and the way these narratives depict the Subjectivation processes of the deaf population.

Keywords: Deafness. Psychology. Politics of Inclusion. Governing

\title{
PSICOLOGÍA Y SORDERA: GOVERNAMIENTO DE LA DIFERENCIA Y OTROS MÁRGENES POSIBLES
}

\begin{abstract}
Resumen
En un momento en que se dice mucho acerca de la inclusión de las personas con discapacidad y la necesidad de prepararse para el ejercicio de esta inclusión, este artículo tiene como objetivo cuestionar en qué momento la sordera se entiende como la discapacidad, que se incorpora a la política pública de una producción de sus conocimientos específicos y científicos. En este sentido, este artículo trata de problematizar la manera como la población sorda se vuelven audiencia de Psicología. Se propone, a través de la discusión, la comprensión de los movimientos de la normatización, la normalización y lo governamento de la diferencia, con el objetivo de presentar la posibilidad y/o necesidad de dar una nueva mirada sobre la sordera, a fin de modificar la relación entre la Psicología y la sordera, alejándose de la relación de objeto a sabiendas de que tal reunión se establezca. Así se hará tensar algunos testimonios y discursos presentes en el discurso de los profesionales, la identificación de ese lugar la Psicología habla hoy, y cómo estas narrativas visibilizam procesos de subjetivación de la población sorda.
\end{abstract}

Palavras clave: Sordera. Psicología. Políticas de Inclusión. Governamento.

\section{Referências}

AMARAL, C. T. D. e PARAÍSO, M. A. Modos de subjetivação de surdos/as em práticas curriculares distintas. Contagem/MG, (Sem Ano).

COSTA, T. Comentários em blog - Psicólogos dão atendimento em LIBRAS para surdos. [online]. Disponibilidade www.guiainclusivo.com.br/2011/06/psicologos-dao-atendimentoem-libras-para-surdos/\#comment-616 Acesso: 16 de outubro de 2013.

BATISTA, A. Uma psicóloga com deficiência auditiva. [online]. Disponibilidade: http://cronicasdasurdez.com/uma-psicologa-com-deficiencia-auditiva/. Acesso: 30 de outubro de 2013. 
BISOL, A. C., SIMIONI, J. e SPERB, T. Contribuições da Psicologia Brasileira para o Estudo da Surdez. Psicologia Reflexão e Crítica, Porto Alegre, v.21, n.3, p.392-400. 2008.

BRASIL. Decreto $n^{o} 3298$ de 20 de dezembro: Integração da Pessoa com Deficiência. Brasília/DF. 1999.

BRASIL. Instituto Brasileiro de Geografia e Estatística (IBGE). Ministério do Planejamento, Orçamento e Gestão. 2010a.

BRASIL. Política Nacional de Saúde da Pessoa Portadora de Deficiência. Ministério da Saúde, Secretaria de Atenção à Saúde / Departamento de Ações Programáticas Estratégicas. Brasília/DF. 2010b.

BRASIL. Avanços das Políticas Públicas para as Pessoas com Deficiência: Uma análise a partir das Conferências Nacionais. Presidência da República, Secretaria Nacional de Promoção dos Direitos da Pessoa com Deficiência / Secretaria de Direitos Humanos. Brasília/DF. 2012.

CAMATTI, L.; GOMES, A. P. A captura da cultura e da diferença: articulações a partir de uma política bilíngue para surdos. In: THOMA, da S. A. e HILLESHEIM, B. (Org.) Políticas de Inclusão: gerenciando riscos e governando as diferenças - Santa Cruz do Sul: EDUNISC, p. 163-178, 2011.

FOUCAULT, M. A governamentalidade. In: Microfísica do Poder, p. 163-174. 23 ed. São Paulo: Graal. 2007.

GONÇALVES, P. C. S. Atendimento psicológico para surdos. Revista Virtual de Cultura Surda $e$ Diversidade, [online]. Disponibilidade: http://editora-araraazul.com.br/novoeaa/revista/?p=962. Acesso: 25 de outubro de 2013.

LOPES, M. C. Prefácio: políticas de inclusão e governamentalidade. In: THOMA, S. A. e HILlESHEIM, B. (Org.) Políticas de Inclusão: gerenciando riscos e governando as diferenças - Santa Cruz do Sul: EDUNISC, p. 7-15, 2011.

MORAES, M. PesquisarCOM: política ontológica e deficiência visual. In: M. Moraes e V. Kastrup (Orgs). Exercícios de ver e não ver. p. 15-31. Rio de Janeiro: Nau. 2010.

MORAES, M. O.; LIMA, L.F. F; MANSOIO, C. C. Variações sobre ver e não ver: dois relatos de casos. 2011. Disponível em http://pepsic.bvsalud.org/scielo.php?pid=S180952672011000100011\&script=sci_arttext. Acesso em: 03 de novembro de 2013.

PAULON, S.; FREITAS, L. B. L.; PINHO, G. S. Documento subsidiário à política de inclusão - Brasília: Ministério da Educação, Secretaria de Educação Especial, 2005. Disponível em http://portal.mec.gov.br/seesp/arquivos/pdf/docsubsidiariopoliticadeinclusao.pdf. Acesso em 14 de junho de 2013 às 15 h. 
PERLIN, G. T. T. et al.; História dos surdos. Universidade do Estado de Santa Catarina (UDESC). Florianópolis, 2002.

QUADROS, R. M.; PERLIN, G. T. T. (organizadoras); Estudos Surdos II. Rio de Janeiro: Ed. Arara Azul, 2007.

ROSA, G. A terceira margem do rio. In Primeiras Estórias, p. 32. Rio de Janeiro: Editora Nova Fronteira, 1988.

SOLÉ, M. C. P. O sujeito surdo e a psicanálise: uma outra via de escuta. Porto Alegre: Editora da UFRGS, 2005.

STRÖBEL, K. L. Surdos: vestígios culturais não registrados na história (Dissertação de Mestrado). Florianópolis: UFSC, 2006.

THOMA, A. S.; HILlESHEIM, B. (Orgs). Políticas de Inclusão: gerenciando riscos e governando as diferenças. Santa Cruz do Sul: EDUNISC. 2011.

VEIGA-NETO, A.; LOPES, M. C. Inclusão e governamentalidade. Educ. Soc. vol.28 n. 100 Campinas, 2007.

VEYNE, P. Como se escreve a história. Foucault revoluciona a história. Brasília, Editora da UnB, 1982.

Data de recebimento: 08/01/2014

Data de aceite: $23 / 06 / 15$

\section{Sobre as autoras:}

Liliane Moreira de Oliveira é psicóloga graduada pelo Centro Universitário Metodista do Sul - IPA. Endereço eletrônico: lilianemoliveira@ gmail.com

Oriana Holsbach Hadler é Doutoranda em Psicologia Social e Institucional pela Universidade Federal do Rio Grande do Sul (UFRGS). Mestre em Psicologia Social pela Pontifícia Universidade Católica do Rio Grande do Sul (PUCRS), Psicóloga graduada pela Universidade Católica de Pelotas (UCPel) e pós-graduada na Goldsmiths College - University of London, Inglaterra. Psicodramatista pelo IDH-RS. Integrante do Núcleo E-politcs - Estudos em Políticas e Tecnologias Contemporâneas de Subjetivação pela UFRGS e colaboradora do grupo de pesquisa Psicologia, Políticas Públicas e Subjetivação pela UCDB. Endereço eletrônico: orianahadler@gmail.com 
${ }^{i}$ Atriz e escritora francesa, diretora do Teatro Visual Internacional e embaixatriz da Língua Gestual Francesa. Nascida surda escreveu um livro autobiográfico para contar sua história e sua trajetória antes e depois do acesso à Língua de Sinais.

${ }^{\text {ii }}$ Sistemas de leis que garantiam ao Imperador, poder ilimitado e a submissão dos escravos e colonos. 